\title{
The Feasibility and Acceptability of Using a Wearable UV Radiation Exposure Monitoring Device in Adults and Children: Cross-Sectional Questionnaire Study
}

Elizabeth Sela Nagelhout ${ }^{1 *}$, MPH, PhD; Riley Lensink ${ }^{2 *}$, BS; Angela Zhu ${ }^{2 *}$, BS; Bridget G Parsons ${ }^{2 *}$, MSPH; Jakob $\mathrm{D} \mathrm{Jensen}^{3 *}$, PhD; Yelena P Wu ${ }^{2,4 *}, \mathrm{PhD}$

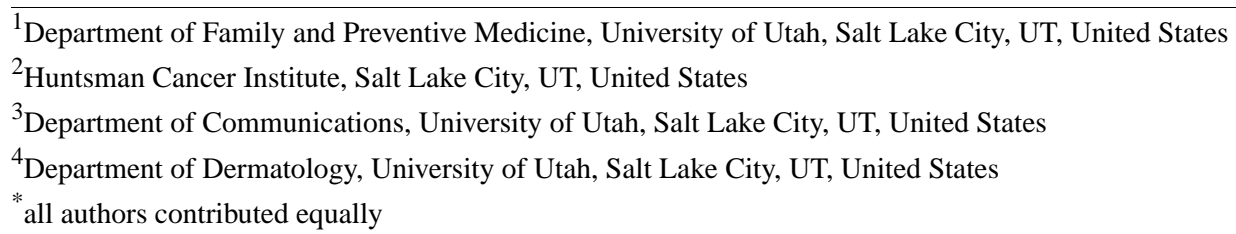

\section{Corresponding Author:}

Yelena P Wu, PhD

Huntsman Cancer Institute

2000 Circle of Hope

Salt Lake City, UT, 84112

United States

Phone: 18012135653

Email: yelena.wu@utah.edu

\begin{abstract}
Background: In the United States, melanoma is the fifth most common type of cancer. Reducing UV radiation (UVR) exposure is essential for the prevention of melanoma. The assessment of individual-level UVR exposure using wearable technology is a promising method to monitor and reduce UVR exposure. However, the feasibility and acceptability of using wearable UVR monitoring devices have not been assessed.

Objective: This study aimed to assess the feasibility and acceptability of using a commercially available UVR monitoring wearable device in adults and children.

Methods: We recruited families ( 1 parent and 1 child) to test a new, commercially available UVR monitoring device (namely, Shade). Participants wore Shade for 2 weeks and completed questionnaires assessing the feasibility and acceptability of wearing the device. Qualitative analyses were conducted to summarize participants' open-ended responses regarding device feasibility.

Results: A total of 194 individuals (97 adults and 97 children) participated in this study. The participating children were aged, on average, 12.7 years. Overall, adults and children reported moderate satisfaction with wearing Shade. The feasibility of the use of Shade was adequate, with 73\% (65/89) of adults and 61\% (54/89) of children reporting that they wore the device "all of the time they were outside." Through open-ended responses, participants reported that the device was easy to use, was compact, and increased their awareness about their exposure to UVR.

Conclusions: Adults and children can feasibly use a wearable UVR monitoring device, and the use of the device was acceptable to participants. The device could be integrated into melanoma preventive interventions to increase individuals' and families' awareness of UVR exposure and to facilitate the use of recommended melanoma preventive strategies.
\end{abstract}

(JMIR Dermatol 2020;3(1):e15711) doi: 10.2196/15711

\section{KEYWORDS}

ultraviolet radiation exposure; wearable device; melanoma; melanoma prevention 


\section{Introduction}

\section{Background}

In the United States, melanoma is the fifth most common type of cancer [1]. Over the past three decades, overall melanoma incidence has increased by $1.5 \%$ each year; the incidence in pediatric populations is increasing, and these trends are expected to continue [1]. Individual UV radiation (UVR) exposure is the primary modifiable risk factor related to melanoma development [2]. The reduction of UVR exposure through the use of sun protection strategies (eg, wearing a sunscreen, wearing long sleeves, and avoiding peak UVR hours from 10 AM to 4 PM) is essential for the prevention of melanoma. Decreasing UVR exposure during childhood is especially critical because $25 \%$ of one's lifetime UVR exposure occurs during childhood, a key period of skin cell development and susceptibility $[3,4]$. Children and adolescents often rely on their parents to engage in sun-safe habits (eg, helping apply a sunscreen, providing long-sleeved shirts for children to wear, and buying a sunscreen for the household), thereby decreasing their UVR exposure, and are more likely to be successful in engaging in these behaviors if their parents model sun-safe habits [5-7]. However, many parents do not provide sufficient sun protection for their children [7]. Furthermore, children often do not use the recommended sun protection strategies to decrease UVR exposure, and they receive multiple sunburns, which can double their lifetime risk of melanoma $[8,9]$.

Typically, the assessment of an individual's UVR exposure has relied on self-reported questionnaires and diaries of sun protection, time spent outdoors, and the number of sunburns [10-13]. However, self-reported measurements of UVR exposure can be upwardly biased because of inaccurate recall and social desirability effects [14-17]. There are few objective assessments of UVR exposure available. The most common method for assessing objectively measured UVR exposure has been through the use of personal electronic dosimeters, which are worn as wristwatches or fixed to clothing and collect individual UVR exposure at instantaneous readings (eg, every second) [18-24]. Previous studies using electronic dosimeters have been limited by the use of dosimeters that detect UV-B only, are not commercially available and thus have a lower likelihood for broader dissemination, have low sensitivity and specificity, and are unable to filter out visible light that could overestimate actual UVR measurements [25-27].

The Shade UVR sensor is a newly developed wearable radiometer, which records both instantaneous readings and accumulated UVR doses over time [26]. The device is capable of measuring both UV-B and UV-A, filtering out visible light, and is weighted according to the erythemal action spectra, which is standardized by the International Commission on Illumination and adopted by the World Health Organization [26,28,29]. Using a standardized unit of UVR exposure allows for the comparability of exposure measurements among study populations. In addition, Shade has documented excellent sensitivity and accuracy, including when compared with other UVR monitoring devices [26]. For example, the accuracy of
Shade is roughly $80 \%$, whereas the accuracy of the Band wearable device is roughly $20 \%$ [26].

\section{Objectives}

Commercially available UVR monitoring devices have the potential to be integrated into melanoma preventive interventions aimed at reducing UVR exposure. For example, such devices could facilitate the self-monitoring of UVR exposure and increase an individual's awareness of their overall UVR exposure levels. In other areas of research and practice, including those focused on increasing physical activity to prevent or treat obesity, self-monitoring of health behaviors (eg, time spent engaging in physical activity) has been shown to be beneficial for positive health behavior changes [30,31]. However, previous studies have not yet assessed the feasibility and acceptability of using a commercially available UVR monitoring device, from participants' perspectives [19,21,32]. Establishing the adequate feasibility and acceptability of such devices is essential before being used in skin cancer preventive interventions aimed at decreasing UVR exposure. The purpose of this study was to examine the feasibility and acceptability of using a newly developed, commercially available UVR monitoring wearable device (ie, Shade) in children and adults.

\section{Methods}

\section{Study Sample}

All study participants were recruited within the state of Utah, which has the highest incidence of melanoma in the United States [33]. Adults were eligible to participate in the study if (1) they were at least aged 18 years, (2) were residents of Utah, (3) had at least one child aged 8 to 17 years who was willing to participate in the study, (4) did not have a pacemaker (because of the strong magnet in the UVR monitoring device), (5) had and were willing to use a Bluetooth or Wi-Fi-enabled mobile phone for research purposes (to communicate with the research staff and synchronized the device), (6) were willing to download and use a free mobile phone app that shared their UVR exposure data with the research team, and (7) were able to read and speak English. Children were eligible to participate if (1) they were aged 8 to 17 years, (2) lived with a primary caretaker in Utah, and (3) did not have a pacemaker. Children who did not have a Bluetooth or Wi-Fi-enabled device that allowed them to share their UVR exposure data with the research team were loaned one for the duration of the study.

A total of 194 participants (97 parent-child dyads) were enrolled in the study. Of the adults who completed eligibility screening, 34 were ineligible. The reasons for ineligibility included the parent not having children aged between 8 and 17 years $(n=28)$, not having a mobile phone with Bluetooth and Wi-Fi $(n=5)$, and being unable to read English $(n=1)$. Of the 116 eligible adults, 7 decided not to participate and 12 were unable to participate because of a limited number of devices available for use within the context of this study. There were no parent-child dyads excluded because of child ineligibility after it was determined that the parent was eligible to participate. Data were collected between June 2018 and October 2018 to capture the experiences of adults and children wearing the device during 
the summer months and once school had started. An institutional review board approved all the study procedures.

\section{Study Procedures}

Before their study enrollment, parental consent, parental permission, and child assent forms were emailed to participants, and Shade was mailed to participants. Once participants received the devices, they provided informed consent by phone. During the consent call, research assistants reviewed instructions on the use and care for the device. Parents and children were each asked to wear Shade clipped to the chest portion of their shirt for 14 days during waking hours. Shade collects the individual, time-stamped standard erythemal dose (SED), a standardized measure of UVR exposure, accumulated over the course of the day and reports readings of the SED every $6 \mathrm{~min}$. The device is 1.58 inches in diameter and weighs 0.48 ounces and can be attached to clothing with a built-in magnet. The data collected by the device were synchronized using the Shade research app. Shade, which is commercially available, is accompanied by an app; however, for the purposes of our research project, we used the Shade research app. The research app did not provide participants any information on their UVR exposure, as we were focused on examining the feasibility and acceptability of wearing the device separately from the UVR feedback feature. The app was used to collect the UV data from the device and to notify participants when the device battery needed to be recharged. The participants were also instructed to avoid getting the device wet (as it is not waterproof), to synchronize the device to the Shade research app daily, and to recharge their device at least every 3 days. At the start of the 14-day study period, parents and children were asked to complete a baseline questionnaire that included items assessing demographic information. They were also asked to complete once-daily questionnaires assessing whether they had worn the device. Finally, parents and children were asked to complete an exit questionnaire assessing the feasibility and acceptability of wearing Shade. Parents and children reported on their own use of the device separately. Feasibility and acceptability were conceptually defined based on previous research [34,35]. Feasibility was defined as "Are participants capable of and willing to integrate wearing the Shade device into their daily lives?" Acceptability was defined as "To what extent wearing the Shade device was judged as suitable, satisfying, or attractive to study participants?"

\section{Feasibility}

Feasibility was assessed through four multioption quantitative items and two open-ended questions. The quantitative items included the following: (1) "During days you wore the Shade device, how much of the time between 7 am and $7 \mathrm{pm}$ did you wear the device when you were outside?" (eg, "wearing it $1 / 4$ of the time" and "wearing it all of the time"); (2) "When did you wear the Shade device?" (eg, "I put it on in the morning and wore it all day [except in the shower or while swimming], and took it off again in the evening" and "I wore it most of the time but took it off at special occasions"); (3) "When you wore the Shade device, did you pay attention to it?" (eg, "Yes, I was aware that it should be clipped to my clothing, exposed to the sun, but I didn't change my behavior because of it" and "No, I didn't pay attention to it at all"); and (4) "While you wore the Shade device, did people around you notice it and ask you what it was for?" (eg, "yes, many" and "no, no one"). Open-ended feasibility questions assessed perceptions of enjoyment and usability and included the following questions: "What did you like about the Shade device?" and "What were some of the challenges of wearing the Shade device?"

\section{Acceptability}

The acceptability of using Shade was measured using a 17-item modified questionnaire that assessed the perceptions of comfort, enjoyment, privacy, and usefulness of the device [34]. The original questionnaire was modified to focus on the acceptability of wearing the device. Responses were measured on a 5-point Likert-type scale, scored 1 to 5, ranging from strongly disagree to strongly agree. For example, participants were asked to rate how much they agreed with items such as "I think the device was comfortable." All questionnaires were administered using Research Electronic Data Capture (REDCap) [36,37].

\section{Analytic Plan}

Descriptive statistics were calculated to summarize participant demographic characteristics and to report the proportions of participants' responses to quantitative feasibility and acceptability questions. Means and standard deviations were calculated to summarize the number of days the device was worn. The qualitative feasibility questions were coded using content analysis to identify common themes describing what parents and children liked about the device (eg, ease of use and awareness of their UVR exposure) and challenges they experienced when wearing the device (eg, the device falling off) [38]. The codebook was created by three research team members based on the initial coding of $10 \%$ of parents' and children's responses for each of the two open-ended feasibility questions. Overall, 50\% of all parents' and children's responses were coded by two independent coders (percent agreement $=95 \%$ ). All discrepancies in coding were discussed and resolved by the coders before commencing the analysis.

\section{Results}

\section{Demographic Characteristics}

A total of 97 adults and 97 children ( $\mathrm{N}=194$ individuals) participated in this study. Among adults, 87\% (83/95) were non-Hispanic white and 5\% (5/95) were Hispanic and $77 \%$ (73/95) were women (Table 1). The average age of participating children was 12.7 years (SD 2.6), 85\% (81/95) were non-Hispanic white and $8 \%(8 / 95)$ were Hispanic and $59 \%$ $(56 / 95)$ were female (Table 1$)$. 
Table 1. Demographic characteristics of participants.

\begin{tabular}{|c|c|c|}
\hline Characteristics & Adults ( $\mathrm{n}=97)$ & Children $(n=97)$ \\
\hline Age (years), mean (SD) & $41.6(6.3)$ & $12.7(2.7)$ \\
\hline \multicolumn{3}{|l|}{ Sex, n (\%) } \\
\hline Male & $22(23)$ & $39(41)$ \\
\hline Female & $73(77)$ & $56(59)$ \\
\hline \multicolumn{3}{|l|}{ Race, $\mathrm{n}(\%)$} \\
\hline Non-Hispanic white & $83(87)$ & $81(85)$ \\
\hline Hispanic & $5(5)$ & $8(8)$ \\
\hline Asian or Asian American & $5(5)$ & $4(4)$ \\
\hline Other & $2(2)$ & $2(2)$ \\
\hline \multicolumn{3}{|l|}{ Marital status, n (\%) } \\
\hline Married or marriage-like relationship & $84(88)$ & $\mathrm{N} / \mathrm{A}^{\mathrm{a}}$ \\
\hline Divorced/separated & $9(10)$ & N/A \\
\hline Widowed & $2(2)$ & N/A \\
\hline \multicolumn{3}{|l|}{ Level of education, $n(\%)$} \\
\hline High school graduate or General Educational Development & $8(8)$ & N/A \\
\hline Vocational or technical school & $8(8)$ & N/A \\
\hline Some college, including 2-year degree & $33(35)$ & N/A \\
\hline Bachelor's degree & $25(26)$ & N/A \\
\hline Master's/doctoral degree & $21(22)$ & N/A \\
\hline \multicolumn{3}{|l|}{ Family income, $n(\%)$} \\
\hline$<$ US $\$ 50,000$ & $23(24)$ & N/A \\
\hline$>$ US $\$ 50,000$ & $64(67)$ & N/A \\
\hline I would rather not report this & $8(8)$ & N/A \\
\hline \multicolumn{3}{|l|}{ Occupation location, $\mathbf{n}(\%)$} \\
\hline Mainly indoors & $82(86)$ & N/A \\
\hline Mainly outdoors & $9(9)$ & N/A \\
\hline In a motor vehicle & $3(3)$ & N/A \\
\hline
\end{tabular}

${ }^{\mathrm{a}} \mathrm{N} / \mathrm{A}$ : not applicable (not asked of children).

\section{Acceptability of a UV Radiation Monitoring Device}

Parents and children reported moderate levels of satisfaction with wearing Shade. Parents agreed or strongly agreed that the device was well suited for their bodies $(45 / 89,51 \%)$, was comfortable $(57 / 89,64 \%)$, and was easy to wear $(68 / 69,76 \%$;
Table 2). More than $80 \%$ (73/88) of children agreed or strongly agreed that the device was easy to wear. Only $8 \%$ (7/89) of parents and 17\% (15/88) of children agreed or strongly agreed that the device felt weird physically (Table 2). Only 25\% (22/89) of parents agreed or strongly agreed that they would purchase the device. 
Table 2. Parent's and children's reported acceptability of Shade, a UV radiation monitoring device.

\begin{tabular}{|c|c|c|}
\hline \multirow[t]{2}{*}{ Acceptability of Shade } & \multicolumn{2}{|c|}{ Agree or strongly agree } \\
\hline & Parents, n (\%) & Children, n (\%) \\
\hline Wearing the device feels weird physically & $7(8)$ & $15(17)$ \\
\hline I think the device is well suited for my body & $45(51)$ & $39(44)$ \\
\hline I think the device was comfortable & $57(64)$ & $33(38)$ \\
\hline I think the device was boring & $57(64)$ & $13(15)$ \\
\hline I think the device was annoying & $19(21)$ & $28(32)$ \\
\hline I think the device was pleasant & $20(23)$ & $23(26)$ \\
\hline I think the device may threaten my privacy & $3(3)$ & $4(5)$ \\
\hline If most people in my environment used the device, I would be more inclined to use it as well & $24(27)$ & $32(36)$ \\
\hline $\begin{array}{l}\text { If people who are influential in my life recommended that I use the device for a period of time, I would } \\
\text { do so }\end{array}$ & $43(48)$ & $46(52)$ \\
\hline I think I would wear the device only if I were forced to & $14(16)$ & $12(14)$ \\
\hline If it were launched on the market at an affordable price, I would likely purchase it & $22(25)$ & $15(17)$ \\
\hline If the device were available to me, I would use it & $44(49)$ & $37(42)$ \\
\hline It seems tiresome to use the device & $26(29)$ & $16(18)$ \\
\hline It seems easy to wear the device & $68(76)$ & $73(83)$ \\
\hline The device would be incompatible with most aspects of my activities & $11(12)$ & $26(30)$ \\
\hline The device limits the way in which I like to perform my activities & $8(9)$ & $14(16)$ \\
\hline The device could improve the quality of my activities & $15(17)$ & $12(14)$ \\
\hline
\end{tabular}

\section{Feasibility of Using a UV Radiation Monitoring Device}

Parents reported wearing Shade for an average of 12.7 days (SD 2.54) out of 14 days, and children reported wearing their device for an average of 12.2 days (SD 3.03) out of 14 days. The majority of parents $(65 / 89,73 \%)$ and children $(54 / 89,61 \%)$ reported that they wore Shade whenever they were outdoors between $7 \mathrm{AM}$ and $7 \mathrm{PM}$ during the study period. When asked when they wore the device during the day, $80 \%$ (72/90) of parents and $71 \%$ (63/89) of children reported that they put it on in the morning and wore it all day and took it off again in the evening, indicating full compliance with the study protocol.

The vast majority of the sample $(89 / 97,92 \%$ of parents and $87 / 97,90 \%$ of children) provided responses to the open-ended feasibility questions. The most commonly endorsed themes regarding what participants liked about Shade were the device's ease of use and compact size and that the device increased the participant's awareness about their sun-safe habits and tracked their UVR exposure (see Multimedia Appendix 1). The most commonly endorsed challenges of wearing Shade among parents and children included keeping the device's UVR sensor uncovered (eg, by clothing), remembering to wear the device, its impact on daily activities (eg, the device was in the way while doing chores and the device tugged on shirts), and the device inadvertently falling off. Another challenge mentioned by parents and children included receiving questions from others about the device (Multimedia Appendix 1).

\section{Discussion}

\section{Principal Findings}

The results of this study indicate that the use of a wearable UVR monitoring device was moderately acceptable and feasible for adults and children. In addition, parents and children were, on average, adherent to wearing the device for the vast majority of the desired monitoring days, indicating the potential for the use of monitoring devices in future melanoma prevention interventions. Although participants found wearing the device to be both acceptable and feasible, the results of this study indicated some ways in which the device could be improved for future use.

Exposure to UVR is the primary modifiable risk factor for melanoma [39]. Despite public health efforts to increase the awareness of the harmful effects of UVR through educational interventions, adults and adolescents continue to report experiencing sunburns and do not adhere to sun protection use (eg, wearing sunscreen or long sleeve shirts) [40]. The use of a feasible and acceptable UVR monitoring device, similar to the one assessed in this study, may be beneficial when combined with other health behavior strategies (eg, wearing a sunscreen and avoiding peak UVR hours) in driving behavior changes to reduce UVR exposure. Although participants were not provided with UVR exposure data in real time, $33 \%$ of adults and $9 \%$ of children reported that wearing the device made them more aware of their outdoor sun habits. More than $11 \%$ of children reported that they liked the device because it was able to track their UVR exposure. These findings suggest participants may be interested in using a wearable UVR exposure device to monitor their UVR 
exposure. Future studies may be helpful in identifying whether users find it feasible and acceptable to monitor their UVR exposure through the use of a monitoring device and an integrated UVR feedback system (eg, a phone app or device display). Our team is currently designing interventions to provide participants with personalized UVR feedback in real time in an effort to promote sun protection use.

Self-monitoring of health behaviors via objective measures has been shown in other populations to increase the awareness of behaviors such as sedentary periods and to counter self-reported underestimates of the time spent in sedentary activities [41]. Similarly, in the context of UVR exposure, it is likely that individuals do not have an accurate perception of the amount of UVR exposure they receive. For example, one study reported that a participant's perception of being in the sun for a long period could range from $30 \mathrm{~min}$ to an entire day, which would vastly affect the amount of UVR exposure they received [42]. Providing feedback on the amount of UVR exposure received during daily activities and accumulated throughout the course of an entire day could help individuals have a more accurate sense of their UVR exposure. Knowledge of one's daily UVR exposure will likely become increasingly important, as the overall amount of UVR that is reaching the earth's surface is increasing because of ozone depletion, which puts people at a greater risk for the harmful effects of UVR $[43,44]$.

The results of this study also raised considerations for modifications of UVR monitoring wearable device technology for use in future research. Participants indicated wearing the device was challenging because they forgot to wear the device, it impacted their daily activities, the device fell off at times, and the device solicited questions from others. These results are similar to findings from other studies evaluating the acceptability of wearing health tracking devices. Previous studies have found that barriers to using a wearable device include remembering to put it on, the inability to wear it during certain activities, the device not being waterproof, fear of losing the device, and increased social tension resulting from peers asking about the device [45-47]. Future devices may be more acceptable to users if the device or associated mobile phone app had an alert function to remind them to put on their device each morning, if the device could be worn as a wristwatch or in another inconspicuous location so as to not attract attention from peers, and if the device was waterproof. Parents and children had differing views about some of the aspects of Shade. For example, $64 \%$ of parents and $37.5 \%$ of children agreed or strongly agreed that the device was comfortable, and $21.0 \%$ of parents and $31.8 \%$ of children found the device to be annoying. These differences may emphasize the need to tailor UVR wearable devices for use in adult and child populations separately.

\section{Strengths and Limitations}

The strengths of this study include the use of a commercially available wearable device, which can be accessed by the general population to track their UVR exposure. This study also included both adults and children, who could both potentially benefit from future interventions using UVR monitoring devices, given that both populations are at risk for UVR exposure. Exploring adults' and children's perceptions of the device's acceptability and feasibility separately helped to elucidate the most important challenges that parents and children may experience when using such devices. For example, remembering to wear the device was a bigger issue for children than for adults, and this information can be considered when developing future interventions and app functions. A limitation of this study was the focus on self-reported compliance to wearing the device. In the future, devices that employ accelerometers or other technologies that objectively assess whether participants were wearing the device would be better monitors for study protocol adherence. Future studies could minimize the potential for missing data due to these factors by emphasizing to participants the importance of regular synchronizing and charging their devices to prevent loss of data. Finally, this study was conducted within a single geographic area, which may reduce the generalizability of the results. Two limitations of Shade include its lack of an accelerometer (used to track compliance) and the lack of a waterproof sensor, making it impossible to be worn while swimming.

\section{Conclusions}

The findings of this study indicate that a wearable UVR monitoring device can be feasibly and acceptably used by both adults and children. The use of a wearable device to monitor UVR exposure is a unique and objective method for quantifying the amount of UVR exposure and could be used to support adults and children in reducing their UVR exposure. Ultimately, decreases in personal UVR exposure could contribute to the prevention of melanoma and other types of skin cancer in the future.

\section{Acknowledgments}

The authors appreciate Peter Kaplan and Emmanuel Dumont for their guidance on and assistance with using Shade in this study. The authors also appreciate Jared Luther for his assistance with data management. This work was supported in part by the National Cancer Institute of the National Institutes of Health (NIH; K07CA196985; YW). This work was also supported in part by a Pilot Project Award from the American Cancer Society Huntsman Cancer Institute Institutional Research Grant (129785-IRG-16-190-01-IRG) and an NIH New Innovator Award (1DP2EB022360-01; JJ). Data for this project were collected using REDCap, which is supported by the National Cancer Institute of the NIH (8UL1TR000105, formerly UL1RR025764). The content is solely the responsibility of the authors and does not necessarily represent the official views of the NIH.

\section{Conflicts of Interest}

None declared. 


\section{Multimedia Appendix 1}

Themes endorsed by parents and children on the open-ended feasibility questions. [DOCX File, 17 KB-Multimedia Appendix 1]

\section{References}

1. Surveillance, Epidemiology, and End Results Program. Cancer Stat Facts: Melanoma of the Skin URL: http://seer.cancer.gov/ statfacts/html/melan.html [accessed 2019-01-01]

2. Armstrong BK, Kricker A. How much melanoma is caused by sun exposure? Melanoma Res 1993 Dec;3(6):395-401. [doi: 10.1097/00008390-199311000-00002] [Medline: $\underline{8161879]}$

3. Whiteman DC, Whiteman CA, Green AC. Childhood sun exposure as a risk factor for melanoma: a systematic review of epidemiologic studies. Cancer Causes Control 2001 Jan;12(1):69-82. [doi: 10.1023/a:1008980919928] [Medline: 11227927]

4. Godar DE, Wengraitis SP, Shreffler J, Sliney DH. UV doses of Americans. Photochem Photobiol 2001 Jun;73(6):621-629. [doi: 10.1562/0031-8655(2001)073<0621:udoa>2.0.co;2] [Medline: 11421067]

5. Dobbinson S, Wakefield M, Hill D, Girgis A, Aitken JF, Beckmann K, et al. Children's sun exposure and sun protection: prevalence in Australia and related parental factors. J Am Acad Dermatol 2012 Jun;66(6):938-947. [doi: 10.1016/j.jaad.2011.06.015] [Medline: 21890234]

6. Hamilton K, Cleary C, White KM, Hawkes AL. Keeping kids sun safe: exploring parents' beliefs about their young child's sun-protective behaviours. Psychooncology 2016 Feb;25(2):158-163. [doi: 10.1002/pon.3888] [Medline: 26101815]

7. Johnson K, Davy L, Boyett T, Weathers L, Roetzheim RG. Sun protection practices for children: knowledge, attitudes, and parent behaviors. Arch Pediatr Adolesc Med 2001 Aug;155(8):891-896. [doi: 10.1001/archpedi.155.8.891] [Medline: $\underline{11483115]}$

8. Balk SJ, Council on Environmental Health, Section on Dermatology. Ultraviolet radiation: a hazard to children and adolescents. Pediatrics 2011 Mar;127(3):e791-e817. [doi: 10.1542/peds.2010-3502] [Medline: 21357345]

9. Geller AC, Colditz G, Oliveria S, Emmons K, Jorgensen C, Aweh GN, et al. Use of sunscreen, sunburning rates, and tanning bed use among more than 10000 US children and adolescents. Pediatrics 2002 Jun;109(6):1009-1014. [doi:

10.1542/peds.109.6.1009] [Medline: 12042536$]$

10. Glanz K, Steffen AD, Schoenfeld E, Tappe KA. Randomized trial of tailored skin cancer prevention for children: the Project SCAPE family study. J Health Commun 2013;18(11):1368-1383 [FREE Full text] [doi: 10.1080/10810730.2013.778361] [Medline: 23806094]

11. Lucas RM, Valery P, van der Mei I, Dwyer T, Pender MP, Taylor B, Ausimmune Investigator Group. Sun exposure over a lifetime in Australian adults from latitudinally diverse regions. Photochem Photobiol 2013;89(3):737-744. [doi: 10.1111/php.12044] [Medline: 23311500]

12. Glenn BA, Lin T, Chang LC, Okada A, Wong WK, Glanz K, et al. Sun protection practices and sun exposure among children with a parental history of melanoma. Cancer Epidemiol Biomarkers Prev 2015 Jan;24(1):169-177 [FREE Full text] [doi: $10.1158 / 1055-9965 . E P I-14-0650]$ [Medline: 25587110]

13. Stump TK, Aspinwall LG, Taber JM, Edwards R, Leachman SA. Protection-Adjusted Length of Exposure (PALE): A New Self-Report Measure of UVR Exposure That Captures Multiple Modalities of Photoprotection. In: Paper Presented at the Annual Meeting of the Melanoma Genetics Consortium. 2013 Presented at: GenoMEL'13; June 2013; Philadelphia, PA.

14. McCarty CA. Sunlight exposure assessment: can we accurately assess vitamin D exposure from sunlight questionnaires? Am J Clin Nutr 2008 Apr;87(4):1097S-1101S. [doi: 10.1093/ajen/87.4.1097S] [Medline: 18400741]

15. O'Riordan DL, Stanton WR, Eyeson-Annan M, Gies P, Roy C. Correlations between reported and measured ultraviolet radiation exposure of mothers and young children. Photochem Photobiol 2000 Jan;71(1):60-64. [doi: 10.1562/0031-8655(2000)071<0060:cbramu>2.0.co;2] [Medline: 10649890]

16. O'Riordan DL, Lunde KB, Steffen AD, Maddock JE. Validity of beachgoers' self-report of their sun habits. Arch Dermatol 2006 Oct;142(10):1304-1311. [doi: 10.1001/archderm.142.10.1304] [Medline: 17043185]

17. Rampen FH, Fleuren BA, de Boo TM, Lemmens WA. Unreliability of self-reported burning tendency and tanning ability. Arch Dermatol 1988 Jun;124(6):885-888. [Medline: 3377517]

18. Grandahl K, Mortensen OS, Sherman DZ, Køster B, Lund P, Ibler KS, et al. Solar UV exposure among outdoor workers in Denmark measured with personal UV-B dosimeters: technical and practical feasibility. Biomed Eng Online 2017 Oct 10;16(1):119 [FREE Full text] [doi: 10.1186/s12938-017-0410-3] [Medline: 29017484]

19. Bodekær M, Petersen B, Philipsen PA, Heydenreich J, Thieden E, Wulf HC. Sun exposure patterns of urban, suburban, and rural children: a dosimetry and diary study of 150 children. Photochem Photobiol Sci 2015 Jul;14(7):1282-1289. [doi: 10.1039/c5pp00052a] [Medline: 26066309]

20. Thieden E, Agren MS, Wulf HC. Solar UVR exposures of indoor workers in a Working and a Holiday Period assessed by personal dosimeters and sun exposure diaries. Photodermatol Photoimmunol Photomed 2001 Dec;17(6):249-255. [doi: $\underline{10.1034 / j .1600-0781.2001 .170601 . x]}$ [Medline: $\underline{11722749}$ ] 
21. Thieden E, Philipsen PA, Heydenreich J, Wulf HC. UV radiation exposure related to age, sex, occupation, and sun behavior based on time-stamped personal dosimeter readings. Arch Dermatol 2004 Feb;140(2):197-203. [doi: 10.1001/archderm.140.2.197] [Medline: 14967793]

22. Thieden E, Philipsen PA, Wulf HC. Ultraviolet radiation exposure pattern in winter compared with summer based on time-stamped personal dosimeter readings. Br J Dermatol 2006 Jan;154(1):133-138. [doi: 10.1111/j.1365-2133.2005.06961.x] [Medline: 16403106]

23. Hacker E, Horsham C, Vagenas D, Jones L, Lowe J, Janda M. A mobile technology intervention with ultraviolet radiation dosimeters and smartphone apps for skin cancer prevention in young adults: randomized controlled trial. JMIR Mhealth Uhealth 2018 Nov 28;6(11):e199 [FREE Full text] [doi: 10.2196/mhealth.9854] [Medline: $\underline{30487115}$ ]

24. King L, Xiang F, Swaminathan A, Lucas RM. Measuring sun exposure in epidemiological studies: Matching the method to the research question. J Photochem Photobiol B 2015 Dec;153:373-379. [doi: 10.1016/j.jphotobiol.2015.10.024] [Medline: 26555640]

25. Allen MW, McKenzie RL. National Institute of Water and Atmospheric Research. 2010. Electronic UV Dosimeters for Research and Education URL: https://niwa.co.nz/sites/niwa.co.nz/files/electronic uv dosimeters.pdf [accessed 2019-01-01]

26. Banerjee S, Hoch EG, Kaplan PD, Dumont EL. A Comparative Study of Wearable Ultraviolet Radiometers. In: Proceedings of the 2017 IEEE Life Sciences Conference. 2017 Presented at: LSC'17; December 13-15, 2017; Sydney, Australia. [doi: 10.1109/LSC.2017.8268131]

27. Webb AR. Measuring UV radiation: a discussion of dosimeter properties, uses and limitations. J Photochem Photobiol B 1995 Nov;31(1-2):9-13. [doi: 10.1016/1011-1344(95)07162-4]

28. Webb AR, Slaper H, Koepke P, Schmalwieser AW. Know your standard: clarifying the CIE erythema action spectrum. Photochem Photobiol 2011;87(2):483-486. [doi: 10.1111/j.1751-1097.2010.00871.x] [Medline: 21366601]

29. World Health Organization. Ultraviolet Radiation and Health URL: http://www.who.int/uv/uv_and_health/en/ [accessed 2019-01-01]

30. Lewis ZH, Lyons EJ, Jarvis JM, Baillargeon J. Using an electronic activity monitor system as an intervention modality: A systematic review. BMC Public Health 2015 Jun 24;15:585 [FREE Full text] [doi: 10.1186/s12889-015-1947-3] [Medline: 26104189]

31. Ridgers ND, McNarry MA, Mackintosh KA. Feasibility and effectiveness of using wearable activity trackers in youth: a systematic review. JMIR Mhealth Uhealth 2016 Nov 23;4(4):e129 [FREE Full text] [doi: 10.2196/mhealth.6540] [Medline: 27881359]

32. Køster B, Søndergaard J, Nielsen JB, Allen M, Bjerregaard M, Olsen A, et al. Feasibility of smartphone diaries and personal dosimeters to quantitatively study exposure to ultraviolet radiation in a small national sample. Photodermatol Photoimmunol Photomed 2015 Sep;31(5):252-260. [doi: 10.1111/phpp.12179] [Medline: 25850335]

33. Centers for Disease Control and Prevention. US Cancer Statistics Data Visualizations Tool URL: https://www.cdc.gov/ cancer/uscs/dataviz/index.htm [accessed 2019-01-01]

34. Bowen DJ, Kreuter M, Spring B, Cofta-Woerpel L, Linnan L, Weiner D, et al. How we design feasibility studies. Am J Prev Med 2009 May;36(5):452-457 [FREE Full text] [doi: 10.1016/j.amepre.2009.02.002] [Medline: 19362699]

35. Spagnolli A, Guardigli E, Orso V, Varotto A, Gamberini L. Measuring User Acceptance of Wearable Symbiotic Devices: Validation Study Across Application Scenarios. In: Proceedings of the International Workshop on Symbiotic Interaction. 2015 Presented at: Symbiotic'15; October 7-8, 2015; Berlin, Germany p. 87-98. [doi: 10.1007/978-3-319-13500-7 7]

36. Harris PA, Taylor R, Thielke R, Payne J, Gonzalez N, Conde JG. Research electronic data capture (REDCap)--a metadata-driven methodology and workflow process for providing translational research informatics support. J Biomed Inform 2009 Apr;42(2):377-381 [FREE Full text] [doi: 10.1016/j.jbi.2008.08.010] [Medline: 18929686]

37. Harris PA, Taylor R, Minor BL, Elliott V, Fernandez M, O'Neal L, REDCap Consortium. The REDCap consortium: Building an international community of software platform partners. J Biomed Inform 2019 Jul;95:103208. [doi: 10.1016/j.jbi.2019.103208] [Medline: 31078660]

38. Elo S, Kyngäs H. The qualitative content analysis process. J Adv Nurs 2008 Apr;62(1):107-115. [doi: 10.1111/j.1365-2648.2007.04569.x] [Medline: 18352969$]$

39. Cancer Treatment Centers of America. Risk Factors for Skin Cancer URL: https://www.cancercenter.com/cancer-types/ skin-cancer/risk-factors [accessed 2019-01-01]

40. Centers for Disease Control and Prevention. 2019. Skin Cancer: Behavior Rates: Sunburns URL: https://www.cdc.gov/ cancer/skin/statistics/behavior/sunburns.htm [accessed 2019-01-01]

41. Stubbs B, Williams J, Gaughran F, Craig T. How sedentary are people with psychosis? A systematic review and meta-analysis. Schizophr Res 2016 Mar;171(1-3):103-109. [doi: 10.1016/j.schres.2016.01.034] [Medline: 26805414]

42. Shuk E, Burkhalter JE, Baguer CF, Holland SM, Pinkhasik A, Brady MS, et al. Factors associated with inconsistent sun protection in first-degree relatives of melanoma survivors. Qual Health Res 2012 Jul;22(7):934-945 [FREE Full text] [doi: 10.1177/1049732312443426] [Medline: 22645220]

43. Diffey B. Climate change, ozone depletion and the impact on ultraviolet exposure of human skin. Phys Med Biol 2004 Jan 7;49(1):R1-11. [doi: 10.1088/0031-9155/49/1/r01] [Medline: 14971768] 
44. Linos E, Swetter SM, Cockburn MG, Colditz GA, Clarke CA. Increasing burden of melanoma in the United States. J Invest Dermatol 2009 Jul;129(7):1666-1674 [FREE Full text] [doi: 10.1038/jid.2008.423] [Medline: 19131946]

45. Ridgers ND, Timperio A, Brown H, Ball K, Macfarlane S, Lai SK, et al. Wearable activity tracker use among Australian adolescents: usability and acceptability study. JMIR Mhealth Uhealth 2018 Apr 11;6(4):e86 [FREE Full text] [doi: 10.2196/mhealth.9199] [Medline: 29643054]

46. Schaefer SE, Ching CC, Breen H, German JB. Wearing, thinking, and moving: testing the feasibility of fitness tracking with urban youth. Am J Health Educ 2016;47(1):8-16. [doi: 10.1080/19325037.2015.1111174]

47. Schaefer SE, van Loan M, German JB. A feasibility study of wearable activity monitors for pre-adolescent school-age children. Prev Chronic Dis 2014 May 22;11:E85 [FREE Full text] [doi: 10.5888/pcd11.130262] [Medline: 24854236]

\section{Abbreviations \\ NIH: National Institutes of Health \\ REDCap: Research Electronic Data Capture \\ SED: standard erythemal dose \\ UVR: UV radiation}

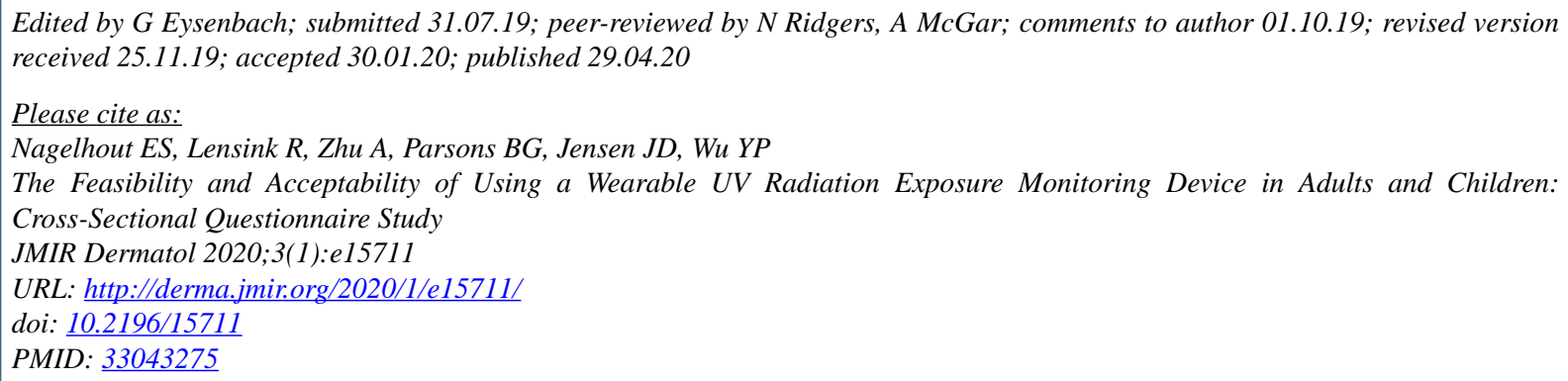

CElizabeth Sela Nagelhout, Riley Lensink, Angela Zhu, Bridget G Parsons, Jakob D Jensen, Yelena P Wu. Originally published in JMIR Dermatology (http://derma.jmir.org), 29.04.2020. This is an open-access article distributed under the terms of the Creative Commons Attribution License (https://creativecommons.org/licenses/by/4.0/), which permits unrestricted use, distribution, and reproduction in any medium, provided the original work, first published in JMIR Dermatology Research, is properly cited. The complete bibliographic information, a link to the original publication on http://derma.jmir.org, as well as this copyright and license information must be included. 